Chapter 7

\title{
EUROPE-ASIA STUDIES: THE CONTRIBUTION OF COMPARATIVE REGIONAL INTEGRATION
}

Philomena MURRAY and Alex WARLEIGH-LACK

\begin{abstract}
This chapter examines the contribution of comparative regional integration studies, with particular reference to EU-Asia relations. The chapter has three core purposes. First and briefly - it asks why scholars should study regions, regionalism and regional integration comparatively and also sets out how we understand the key terms here, that is regions and regional integration. Second, it asks how, once the matters of why and what to compare have been addressed successfully, scholars can actually go about comparative study of regions in the global polity. Finally, it sets out how comparative regional integration studies can contribute and provide fruitful research pathways capable of contributing much to Europe-Asia studies.
\end{abstract}

\section{INTRODUCTION}

This chapter has three core purposes. First - and briefly - it asks why scholars should study regions, regionalism and regional integration comparatively and also set out how we understand the key terms here, that is regions and regional integration. Second, it asks how, once the matters of why and what to compare have been addressed successfully, scholars can actually go about comparative study of regions in the global 
polity. Finally, it sets out how comparative regional integration studies can contribute to Europe-Asia investigations.

\section{WHAT ARE REGIONS, AND WHY STUDY THEM COMPARATIVELY?}

\section{Defining regions}

In much social science terms and concepts are contested; this is certainly true in the field of regionalism/regional integration (De Lombaerde et al. 2010), which is often subject to differing approaches that stem from discrete disciplines. Hence, it is necessary to provide an understanding of several key terms as a proposal for how different terms might be understood and used. This is vital for clear comparison, even if particular scholars might prefer to use any given term differently from the way set out here. In the context of this Handbook, it is also vital in order to both provide an understanding of regions in comparative perspective and to place the relationship between the EU and the Asian region in context, given the often problematic challenges in EU-Asia interregional relations.

There is significant difficulty in defining the term 'region', and this is particularly pertinent in examining European and Asian regions. There is the obvious confusion between micro-regions, that is, those which exist 'below' the level of the state such as provinces or states in federations, and 'macro-regions', which exist at the global level. The latter tend to cover the territory of several states, either entirely or, in the case of cross-border regions, to include parts of the territory of several states (Van Langenhove 2011). To complicate matters further, macro-regions can enter into relations with each 
other, creating the phenomenon of inter-regionalism. Hettne (2005: 279) distinguishes between 'trans-regionalism', where informal processes exist to mediate between different regions, and 'inter-regionalism', where formal institutions are created to conduct an ongoing process of dialogue and collaboration between regions, such as the Asia-Europe Meeting (ASEM). In terms of their positions in the international/global system, regions can be 'core', 'intermediate' or 'peripheral' (Hettne 2001). Core regions are those such as (Western) Europe, East Asia or North America, which are politically strong, economically robust - at least relatively - and whose states enjoy significant control of the world political economy. Intermediate regions are those such as Latin America, which tend to mimic a core region and aim to become part of the core themselves once they have developed sufficiently in economic and political terms. Peripheral regions are those which are 'politically turbulent and economically stagnant' (Hettne 2001: 4), such as the Middle East. There may be one or several regional organizations operating in each of these regions in the global political economy.

How then can we understand what a region is? Several scholars have argued that there are no natural regions in international politics. Thus we cannot simply apply a geographical definition, although geography is certainly important; regions are instead 'forged and constructed by the application of different norms, principles, identities and imaginations of the various actors involved' (Wunderlich 2004: 30). Even in an age of globalization, moreover, the local still matters: perhaps we must accept that regions will continue to differ according to local or domestic norms, values and identities (Duina 2006). Other scholars have proposed new definitions intended to bridge the gaps between various scholarly communities in the field (see for instance Warleigh-Lack's (2006) definition of 'regionalization' and set of variables for comparative analysis of 
regional organizations); although as yet none of these has gained general acceptance, scholars continue to forge fruitful interdisciplinary dialogues (Murray 2010a). What remains to guide research is a further typology developed by Björn Hettne, in which his concept of 'region-ness' is elaborated as a means to gain purchase on an otherwise extremely varied, variable and evolving phenomenon (see Table 6.1).

For Hettne, and his frequent collaborator Fred Söderbaum, region-ness is a fluid concept, a spectrum or process which contains several possibilities, and within which any given region may travel. It is 'the process whereby a geographical area is transformed from a passive object to an active subject capable of articulating the transnational interests of the emerging region' (Hettne and Söderbaum 2000: 461).

\section{[TABLE 6.1 ABOUT HERE]}

These various categories of region-ness are not intended to be hierarchical - none is seen as normatively preferable to others, and any region is considered to be capable of movement along the scale in either direction; for instance, a regional state could become a regional community, and a regional complex could become a regional society - or indeed remain a complex, or transform into a regional space. As a typology, it is immensely helpful, and various approaches can be taken to understand whether and how a given region fits into it at any given point. ${ }^{1}$ For example, Stephen Calleya argues that political, social, cultural and trade flows give a de facto delimitation of a region (Calleya 1997); a similar case is made by Schulz, Söderbaum and Öjendal (2001), who argue scholars should focus on processes of regionalization rather than a specific institutional model or a priori definition of region (see also Söderbaum 2009). 


\section{Defining regionalism and integration}

As a general guide, Fawcett and Gandois (2010) present a helpful distinction between regionalism (a political project of region-creation), regionalization (a process of regionformation which may be bottom-up), and regional integration (which they consider a broader and more complex process of economic and social transformation). This taxonomy is useful in helping observers understand what is at stake in a given process of region-building, and why it is happening. Our usage of the terminology here is slightly different. Regional integration was generally considered a suitable term for the 'first wave' of regional projects which arose after the end of World War II, but the failure - or lack of momentum - of such processes outside Europe, and ultimately in Europe itself, to match the predictions and aspirations of the neofunctionalists was ultimately considered by those theorists to sound the death-knell for the concept in its strictest sense (Haas 1961; Haas 1975). Indeed, few scholars use the term today with the full force of the early neofunctionalist intention (Chryssochoou 2008). The authors' view, which colours our usage of the term, is that 'regional integration' can be used as a catch-all device or broad framework to describe the process and products of regionbuilding, so long as it is understood in a pluralistic, fluid way in keeping with Hettne's typology of 'region-ness'. ${ }^{2}$ We thereby seek to avoid the often circuitous debates on definition and the disciplinary narrowness of some of the discussions. Yet we applaud efforts to define regions, regionalism and regionalization, such as Bridges' definition of regionalism as the tendency to create institutions or at least mechanisms to assist in the interaction and regionalization as the process of interaction within a region (Bridges 2004: 387) and Beeson's (2005: 971) distinction between regionalism as 'the political 
process in which states drive co-operative initiatives', and regionalization as 'the processes of economic integration which, while they may be influenced by state policies, are essentially uncoordinated consequence of private sector activities'.

\section{The value of comparison}

As the meta-theoretical and conceptual issues raised by the comparative study of regions and regional integration have been explored in detail elsewhere (Warleigh-Lack and Rosamond 2010; Robinson 2011) we seek here to make several broad-brush statements. First, comparison is essential if scholars are to gain a holistic understanding of contemporary regions and regionalism, and thereby avoid elevating what may be specific features of a particular region to the status of a general phenomenon - as has happened in the past, both normatively and descriptively (Söderbaum and Shaw 2003). As the obverse of this argument, only by comparison can we understand what really are distinctive features of particular regions, and thus test claims that they are sui generis, that is, unique or special (Katzenstein 1996). We can then understand whether there are comparable institutional or architectural design principles across regions - and certain design imperatives that are common across regions.

Second, if this comparison has an historical dimension, and we argue that this is essential to the proper understanding of motivations for the creation of regional entities, it can permit scholars to understand the differences and similarities between 'old' and 'new' forms of regionalism, particularly in cases such as the Association of Southeast Asian Nations (ASEAN) or the European Union (EU), which have been part of each 
regionalism 'wave' (Beeson 2005). Without comparative study, how would we know whether new regionalism as a whole, rather than a particular expression of it, was enduring or failing (Laursen 2003)? How could we otherwise tell whether it was reflecting, or even co-shaping, the processes of globalization (Duina 2006)? Furthermore, we understand that regionalism has developed in different ways in different historical contexts, with distinctive drivers in many cases. A comparison of one historical period in one region to another region may have a different time period as comparator, such as a specific threat or crisis. A historical analysis must also examine the building of a regional community and its foundational norms, such as reconciliation, trust and consensus (Murray 2010b). The historical motivations for the creation of a sustainable region may be endogenous and/or exogenous. Endogenous factors could relate to the role of national sovereignty; commitments by founding states to regionalism; economic development; the role of business interests; personal leadership; and whether there is regional rivalry or a leadership deficit. Exogenous factors include the influence of the United States (pertinent in the case of both European integration and Asian security networks); threat perception; and the role of crises as catalysts or impediments.

Third, comparative studies open up possibilities for productive exchange among practitioners of regionalism and between policymakers and scholars. The policy-making community of the various regions can thereby be empowered to refine their means of addressing political, economic and social challenges, perhaps learning from 'best practice' or policy failures elsewhere. Comparative analysis can also bring together policymakers and scholars into useful dialogue, perhaps even forming epistemic communities. 
Fourth, through comparative regionalism scholars are able to build up sufficient evidence to develop and hone their concepts, approaches and understanding, perhaps obtaining new syntheses through this process. In a context such as regionalism/regional integration studies, where both the EU studies and newer regionalist communities are often divided internally as well as separated from each other (Warleigh-Lack and Rosamond 2010), this is essential for the generation of new knowledge, and to enable scholars sundered by sociology of knowledge factors (academic structures) particularly the artificial division between EU studies and international relations communities - to collaborate. The previous artificial division between scholars of Asian regionalism and of EU integration is an example of failure by two sets of scholars to see the comparative potential in each others' research agendas (Murray 2010a).

\section{HOW TO COMPARE REGIONS - A QUALITATIVE APPROACH ${ }^{3}$}

But how exactly should comparison be undertaken once scholars have generated a (working) definition of the term 'region' with which they are happy? Should we prefer quantitative, more rationalist research designs (Genna and de Lombaerde 2010) or qualitative, more constructivist approaches (Van Langenhove 2011)? Both have strengths and weaknesses, and will usually be selected according to a scholar's epistemological preference. Discussions of how to compare often run up against such issues, leading to protracted and ultimately insoluble arguments about which way forward is 'best'. Indeed, debates about what to compare can be as fraught as how to compare - and the two discussions are closely linked. Do we compare across countries, 
events, policies, leadership or institutional design, for example? In what follows, we thus indulge our own preferences, by setting out a qualitative perspective. Our view is that the distinction between nomothetic and idiographic methods in social sciences is instructive here (Van Langenhove 2011).

Drawing on debates in psychology about how unique individuals can be studied both in their own right and to inform generalizable theory (Murray and Kluckhorn 1953; Van Langenhove 2011), we maintain that each region is in certain aspects (i) like all other regions; (ii) like some other regions; and (iii) like no other region. In that sense there should not be a contradiction between idiographic and nomothetic research. It is a matter of whether one is seeking singularities or generalities. Moreover these approaches can be combined: scientific knowledge gathered at the level of a single case can be compared with other single cases. Thus we can avoid the $n=1$ debate regarding the EU and how comparable it might be to Asian regional entities, for example (see Acharya and Johnston 2007). Once there is a large enough collection of such single cases, cross-case comparisons can lead to general theories. This implies that two approaches to doing comparative research can exist: one that stresses the cross-country element, in which you start with collecting information across a sufficiently large number of cases but without the ambition to fully understand each of the single cases, and another which stresses the idiographic element - here you start with detailed single cases that lead to knowledge about the case with the possibility to cross-refer that knowledge with other cases at a later time.

Following Morgan (2005), and also drawing on Fawcett and Gandois (2010), we argue that a distinction between the projects, the processes and the products of 
regions/regionalism/regional integration can be drawn. This permits scholars to see three distinct areas of comparison:

- Processes of region-building: the paths of the actual step-by-step transformations;

- Projects of region-building: the visions of intellectuals, political elites and popular movements;

- Products of regions such as treaties, institutions, policies, practices and trade agreements or security alliances.

In order fully to exploit the possibilities of setting up comparative research projects, however, it is necessary to deepen and broaden the research agenda. Warleigh-Lack and Van Langenhove's suggestions regarding how this can be done, which add flesh to the bones of Fawcett and Gandois' typology, are summarized in Table 6.2.

\section{[TABLE 6.2 ABOUT HERE ]}

The first set of issues identified in Table 6.2 relates to the kinds of state that take part in each region, and how they are structured both internally and within a region with regard to power. Serious comparative examination is warranted regarding the role of the United States' hub-and-spokes approach in the Asia-Pacific and the distinctive approaches it took to the construction of regional bodies in Southeast Asia and Europe. A further aspect of comparison in terms of power, relating to the EU and Asia, is the US 
as a security guarantor in the context of its apparently declining dominance of hard power and the rise of China. This will be a key issue for Asian regionalism, but also for that of Europe regarding the future of NATO and the defence capacities of the EU. With regard to internal structures and use of power, different questions must be asked. Are the states capitalist? If so, which variety of capitalism pertains? Are they authoritarian, or liberal democracies, or based on other regimes? Are they unitary, federal or devolved? How does this influence the way these states understand and design regions, or the goals that they seek to achieve from region-building? What is the role of the elites driving regional agendas? Is regionalism bottom-up or top-down?

The second set of issues brings to the fore both material and non-material factors relating to the context of each region. Has geography dictated limits to the region, or has the latter been constructed to try and transcend the former? Have past events influenced (potential and actual) member states' perceptions of themselves, each other or third countries in a way which impacts upon the region - either positively (facilitating a shared approach to the region, or seeing the region as a means to improve security or to bring about reconciliation or solve transnational territorial conflicts or other disputes), or negatively (preventing trust-building)? To what extent, then, does communitybuilding in regional integration require a predisposition towards trust? How might this involve normative priors (Acharya 2009) to build a community? And can this be achieved by means of architectural or institutional design? What is the normative predisposition that determines or prevents an openness to novel solutions to almost intractable problems $?^{4}$ Is trade the main rationale for regionalism in some, or most, contexts? Do preferential trade agreements constitute a form of regionalism? Are trade relations a major determinant of regionalism? Or can a regional body be successful if 
trade relations remain fragmented or bilateral? In fact, the spate of Free Trade Agreements (FTA) suggests that trade agreements do not necessarily lead to increased regionalism. Dent (2010: 240-1) goes so far as to suggest that there is 'little evidence to date that the dense FTA bilateralism in the Asia-Pacific has made contributions to a more comprehensive regionalized integration and regional community-building processes that can be distinguished from other separate contributing processes at the micro or macro level'. Equally, what of strategic considerations? Can a regional body lastingly be 'based on shared economic and strategic interests' yet also 'highly fractured' and potentially undermined by bilateral agreements, as is arguably the case with ASEAN (Heydon and Woolcock, 2009, 12-13)?

The third set of issues squarely confronts the fact that any region is comparable with different 'others' according to the issue at hand, and that in some cases the best comparison may be with other states rather than other regions (Sbragia and Söderbaum 2010). This implies that a range of fruitful comparisons is both possible and required.

The fourth set of issues for comparative regional integration work asks scholars to look at each region, as well as comparison, in their respective contexts. Regions exist as part of complex webs of structures and processes which combine to govern, or at least shape, the contemporary globe: so regions are not isolated and discrete entities, but rather are interdependent, involved in multilateral and sometimes inter-regional decision making, confronting global challenges and often common concerns (Song 2007: 68). In Europe, for example, the EU coexists with the Council of Europe, NATO, the Organization for Security and Cooperation in Europe and the Nordic Council, to name but four other structures. In Asia, ASEAN co-exists with ASEAN Plus Three (China, 
Japan, South Korea); the ASEAN Regional Forum (ARF) and the East Asian Summit, but also with the Asia Pacific Cooperation Forum (APEC). The study of these regional constellations, or matrices, as a feature - a characteristic? - of regional integration is as yet under-developed. Inter-regionalism is also lifted up for analysis within this issue-set, raising two further issues. The first is the need to explore the links between the internal and external aspects of region-building: internal factors include sovereignty; national interests; national commitments to regionalism; the perception of economic growth and development advantages; the role of business interests; personal leadership, while exogenous factors include the influence of the US on regional actors' perceptions of regionalism as a means to address threats and/or crisis. The second issue in this issue-set is the need to compare how a given region relates to others. Here we might observe the perception of mutual benefit, inter-regional trade agreements, cooperation in multilateral forums, and the self-perception of the region as an international or foreign policy actor. Do states in a region regard multilateralism as more important than regionalism, and, if so, why? What are the historical explanations for this? How clear is the distinction between multilateralism and regionalism, in fact? The Asian region, for example, can be perceived as a form of multilateralism in itself - a set of 'tangled webs' (Tow 2008) of overlapping, multilayered structures that differs markedly from the institutional concerns in the European Union, if less markedly from the spaghetti bowl of pan-continental governance structures in Europe. 


\section{COMPARATIVE REGIONAL INTEGRATION AND EUROPE-ASIA RELATIONS}

We now seek to understand how comparative regional integration studies can contribute to investigations of EU-Asia relations. We recall that significant strategic, economic and political challenges are addressed through regional integration in both continents. The EU and ASEAN are both survivors of 'first wave' regionalism which have adapted to face the challenges of globalization and the post-Cold War period, although in very distinctive ways. Moreover, in addition to bilateral relations between individual states, the inter-regional element of Europe-Asia relations is significant, through the ASEM process as a sustained and long-term vehicle for dialogue, and more importantly, for the socialization of leaders, bureaucrats, epistemic communities and civil society groups. Thus, comparative regional integration analysis has, in principle, much to offer in this regard. We intend what follows as an indicative set of suggestions for fruitful research as part of an ongoing Europe-Asia research project, rather than as a definitive research agenda. We structure our suggestions according to the categories in Table 6.2.

\section{The 'statehood' dimension}

As a first project, it is fruitful to examine the construction of regions as security devices, that is to say, as means of building confidence and institutionalizing conflict management, so as to foster a habit of cooperation (on the often-overlooked matter of the EU qua security policy, see Gardner Feldman 1999). Why and how have elites in Europe and Asia, with their respective national polities, structures, norms and political 
cultures, chosen these particular forms of region? How have strategic interests as well as state cultures played a role in this?

As a related project, it would be intriguing to study whether (liberal) democracy is a sine qua non for 'deep' institutional forms of integration, or whether strategic interests can be a sufficient catalyst (Acharya and Johnston 2007). In other words, can authoritarian states agree formally to share sovereignty in a region, and, if so, in what way? A subsequent project examining the impact of region-building on the substance of democracy would be useful. Is regional integration a means whereby liberal democracy is facilitated through a kind of liberal peace agenda, or a means whereby it is truncated, effectively reducing national or popular sovereignty without constructing an equivalent at regional level? To what extent is democracy essential as a binding principle? Should a democratic type of domestic regime be a core criterion for membership of a regional entity? And how might that be dealt with in a region where democracy is not a universal principle? If a region cannot cohere around democratic principles, what norms and values would be central? Can Asia-Pacific countries really just cohere around pragmatic cooperation? Can 'Asian values' provide the normative structure underpinning the broader structure?

Third, how well do the institutional design and decision-making processes of each region facilitate successful outcomes of regional integration, as identified by their member states? How does participation in regional integration in Europe and Asia impact upon the member states themselves, either normatively or materially? Which elites within the member states drive the regional integration agenda? At what costs? What bargains, trade-offs and compensations are evident in the design of an economic 
community, for example (Murray and Orcalli 2012)? How might these differ from the bargains struck in a security or political community?

\section{The geographical and historical contexts}

In both Europe and Asia, the role of the US has been important in shaping the region, both as part of Washington's foreign policy which shaped national elite choices in security alliances and interdependence, and as a means of 'othering' within the region (for example the European social model, typically contrasted with US free market principles, and Asian values, articulated to distinguish Asia from Western, particularly American, political models and norms). How do the EU, ASEAN and APEC confront the challenges posed by the US as both security-provider and (potential) rival? The creation of the ARF and the East Asia Summit (which now numbers the US and Russia, but not the EU, among its members) are testament to the desire of ASEAN member states and other players in the region to have the US remain embedded in the region. Many Asian players seek to have the US play a potential role as a counterweight to the increasing influence of China, a possible rival to the US hegemon. The US is likely to maintain its hub-and-spoke engagement with Asian states - as a security provider - at the same time that China has become a joiner of Asian regional bodies and a potential threat to some ASEAN states, such as Vietnam, in territorial disputes.

How does the rising importance of China help or hinder the construction of a coherent, functioning region in both Asia and Europe? There are indications that China will be a key player in ASEAN Plus Three in terms of economic regionalism and this is reinforced by the ASEAN-China Free Trade Agreement. To what extent is China a key 
regional hegemon in Asia - and a potential rival in this regard of the US - and a potential threat to effective functioning economic multilateralism in both Europe and Asia? In this regard, China's overwhelming economic influence on the region presents a challenge for effective economic regionalism as well as multilateralism, which remains an important objective of EU foreign policy. How is this linked to historical questions regarding the member states of each region, their worldviews and their interests and threat perceptions? This depends on the extent to which regions engage in sharing perceptions that are 'capable of articulating the transnational interests of the emerging region' (Hettne and Söderbaum 2000: 461).

\section{Combining the nomothetic and the idiographic}

How well does each region respond to significant policy challenges, for example climate change, economic recession, counter-terrorism or territorial disputes? Is there scope for meaningful learning by one region from the other (Chang 2006; Capannelli 2009; Robinson 2011)? We argue that there is indeed such scope and that scholarly endeavours have provided evidence of this (for instance Acharya and Johnston 2007; Warleigh-Lack et al. 2011). Can we draw any more generalizable inferences regarding the utility of regional integration as a problem-solving device? To what extent does the stability of the regional design support problem-solving? Is there, in other words, a habit of cooperation over time across a region? Does one region appear better equipped to deal with those challenges than the other, and if so, why? Is it precisely because of the habits of cooperation? These habits are not only socialization but also habits of decision-making based on qualified majority voting, in the case of the EU, and consensus in the case of ASEAN and ASEAN Plus Three. Problem-solving has no 'one- 
size-fits-all' solution, but we argue that a sign of the maturity of a regional body is its ability to design regional architecture that obliges its member states to work together in a regional bargain based on a balance of interests and values. Evidence of successful regionalism can also bolster the continued existence of a regional entity, and the ongoing crisis of the Eurozone is complemented by a growing legitimacy crisis for the entire European Union at present (Longo and Murray 2012).

\section{Bringing in the intra-and inter-regional dimensions}

For this set of issues, both material and ideational questions matter. In terms of intraregionalism, how do the regional matrices in Europe and Asia combine to promote effective regional governance in each continent, at both regional and national levels? Do they in fact do this, or are there too many overlaps? Conversely, as has been suggested, are there too many organizational gaps and opportunities for decisions to fall between cracks (Calder and Fukuyama 2008)? Second, and with more of an ideational emphasis, do wider visions of identity and interest shape the two regions? How does the EU create or reflect a shared EU identity, as opposed to a more broadly European or Western one? How does ASEAN sit with Asian, East Asian and Asia-Pacific identities? Are identities in Europe and Asia comparable in any way? And how and where do norms fit in normative dispositions or priors to region-building (Acharya 2009) and norms of democracy, human rights and reconciliation? As a related point, how is enlargement of each region determined - who decides who can join later than at the outset, and on what basis? How and why might one region seek to influence the norms and practices of another region in a process of norms entrepreneurship or norms diffusion (Jetschke and Murray 2012)? 
With regard to inter-regionalism, there is scope for more study of the Asia Europe Meeting process: how useful is it as a mechanism and process for developing shared understandings and agendas - as well as various forms of socialization - between the relevant European and Asian states, and non-state actors? How does this compare with other instances of inter-regionalism, for example EU-MERCOSUR, and with bilateral relationships between the relevant states? Are we likely to see greater or lesser efforts to bring scholar together in studies of regions and interregionalism, and if so, why? Certainly, the existence, design and patterns of interregional mechanisms of dialogue and summitry and emergent treaty-style agreements merit further scholarly investigation. Simply because the ASEM now represents over 60 per cent of the world's population and GDP [Gross Domestic Product], it will continue to have relevance. There will be more concerns, however, in the future regarding its mechanism and processes and how it can present a common agenda for interregionalism and effective multilateralism. In terms of trade and investment, there is little likelihood that it is a solution for current failed multilateralism. Yet the habits of cooperation that it has engendered are nonetheless relevant for interregional process-building, so, to borrow a cliché, the jury is out on this question. The above constitutes a fruitful set of research pathways capable of contributing much to Europe-Asia studies. We look forward to the further elaboration of this work as the relationship between the two continents shifts in the coming years. 


\section{REFERENCES}

A. Acharya (2009) Whose Ideas Matter? Agency and Power in Asian Regionalism (Ithaca: Cornell University Press).

A. Acharya and A.I. Johnston (2007) Comparing regional institutions: an Introduction, in: A. Acharya and A.I. Johnston (eds) Crafting Cooperation: Regional International Institutions in Comparative Perspective (Cambridge: Cambridge University Press).

M. Beeson (2005) 'Rethinking Regionalism - Europe and Asia in Comparative Historical Perspective', Journal of European Public Policy 12(6), 969-85.

B. Bridges (2004) 'Learning from Europe: Lessons for Asian Pacific Regionalism?' Asia Europe Journal, 2(3), 387-97.

S. Calleya (1997) Navigating Regional Dynamics in the Post-Cold War World (Aldershot: Dartmouth).

K.E. Calder and F. Fukuyama (eds) (2008) East Asian Multilateralism: Prospects for Regional Stability (Baltimore: Johns Hopkins University Press).

G. Capannelli (2009) 'Asian regionalism: How does it compare to Europe's?', East Asian Forum, 21 April. 
H-J. Chang (2006) 'Industrial policy in East Asia - lessons for Europe', EIB Papers, 11(2), 106-32.

D. Chryssochoou (2008) Theorizing European Integration (2nd edn) (London: Routledge).

P. De Lombaerde, F. Söderbaum, L. Van Langenhove and F. Baert (2010) 'Problems and Divides in Comparative Regionalism', in F. Laursen (ed.) Comparative Regional Integration: Europe and Beyond (Aldershot: Ashgate).

C. Dent (2010) Free trade agreements in the Asia-Pacific a decade on: evaluating the past, looking to the future, International Relations of the Asia-Pacific 10, 201-45.

H. Dorussen, E.J. Kirchner and J. Sperling (2010) 'Conclusion: Structure, Agency and the Barriers to Global Security Governance', in E.J. Kirchner and J. Sperling (eds) National Security Cultures: Patterns of Global Governance (London: Routledge).

F. Duina (2006) The Social Construction of Free Trade: the European Union, NAFTA and MERCOSUR (Oxford and Princeton: Princeton University Press).

L. Fawcett and H. Gandois (2010) 'Regionalism in Africa and the Middle East: Implications for EU Studies', Journal of European Integration 32(6), 617-36. 
L. Gardner Feldman (1999) 'Reconciliation and legitimacy: foreign relations and enlargement of the European Union', in T. Banchoff, M.P. Smith (eds), Legitimacy and the European Union (London: Routledge).

G. Genna and P. De Lombaerde (2010) 'The Small $N$ Methodological Challenges of Analyzing Regional Integration', Journal of European Integration 32(6), 583-95.

E. Haas E. (1975) The Obsolescence of Regional Integration Theory, Berkeley, CA: Institute of International Studies Working Paper No. 25.

(1961) 'International Integration: The European and the Universal Process', International Organization 15, 366-92.

K. Heydon and S. Woolcock (2009) The Rise of Bilateralism. Comparing American, European an Asian Approaches to Preferential Trade Agreements (Tokyo: United Nations Press).

B. Hettne (2005) 'Regionalism and World Order', in M. Farrell, B. Hettne and L. Van Langenhove (eds) Global Politics of Regionalism: Theory and Practice (London: Pluto Press), 269-86.

(2002) 'The Europeanisation of Europe: Endogenous and Exogenous Dimensions', Journal of European Integration 24(4), 325-40. 
(2001) 'Regionalism, Security and Development: A Comparative Perspective', in B. Hettne, H. Inotai and O. Sunkel (eds) Comparing Regionalisms: Implications for Global Development (Basingstoke: Palgrave).

B. Hettne and F. Söderbaum (2000) 'Theorising the Rise of Regionness', New Political Economy 5(3), 457-73.

A. Jetschke and P. Murray (2012) Diffusing Regional Integration: The EU and Southeast Asia, West European Politics, 35(1), 174-91.

P. Katzenstein (1996) 'Regionalism in Comparative Perspective', Cooperation and Conflict 31(2), 123-59.

F. Laursen (2003) 'International Regimes or Would-be Polities? Some Concluding Questions and Remarks', in F. Laursen (ed.) Comparative Regional Integration: Theoretical Perspectives (Aldershot: Ashgate).

M. Longo and P. Murray (2011) No Ode to Joy? Reflections on the European Union's Legitimacy, International Politics, 48(6), 667-90.

G. Morgan (2005) The Idea of a European Superstate (Princeton: Princeton University Press).

H.A. Murray and C. Kluckhohn (1953) Personality in Nature, Society and Culture (New York: Knopf). 
P. Murray (2010a) 'East Asian regionalism and EU studies', Journal of European Integration, 32(6), 597-616.

(2010b) Regionalism and Community: Australia's Options in the Asia-Pacific,

Strategy Paper, Australian Strategic Policy Institute, Canberra.

P. Murray and G. Orcalli (2012) Deepening regionalism in Europe and ASEAN: the role of an economic constitution, Journal of the Asia Pacific Economy 17(3).

N. Robinson (2011) 'Learning from the New Regionalism? What, if anything, can New Regionalist scholarship offer for studies of European Integration?', in A. WarleighLack, N. Robinson and B. Rosamond (eds) New Regionalism and the European Union: Dialogues, Comparisons and New Research Directions (London: Routledge).

M. Schulz, F. Söderbaum and J. Öjendal (2001) 'Introduction: A Framework for Understanding Regionalization', in M. Schulz, F. Söderbaum and J. Öjendal (eds) Regionalization in a Globalizing World (London: Zed Books).

F. Söderbaum (2009) 'Comparative Regional Integration and Regionalism', in T. Landman and N. Robinson (eds) The Sage Handbook of Comparative Politics (London: Sage).

F. Söderbaum and A. Sbragia (2010) 'EU Studies and the "New Regionalism": What Can be Gained From Dialogue?', Journal of European Integration 32(6), 563-82. 
F. Söderbaum and T. Shaw (2003) 'Conclusion: what Futures for New Regionalism?', in F. Söderbaum and T. Shaw (eds) Theories of New Regionalism: A Palgrave Reader (Basingstoke: Palgrave).

W. Song W. (2007) 'Regionalisation, interregional cooperation and global governance', Asia Europe Journal 5, 67-92.

W. Tow (2008) Tangled webs: Security architectures in Asia, Strategy Paper, Australian Strategic Policy Institute, Canberra.

L. Van Langenhove (2011) Building Regions: The Regionalisation of the World Order (London: Ashgate).

A. Warleigh-Lack (2006) 'Towards a Conceptual Framework for Regionalisation: Bridging "New Regionalism" and "Integration Theory", Review of International Political Economy 13(5), 750-71.

A. Warleigh-Lack and B. Rosamond (2010) 'Across the EU Studies-New Regionalism Frontier: Invitation to a Dialogue', Journal of Common Market Studies, 48(4), 9931013.

A. Warleigh-Lack A. and L. Van Langenhove (2010) 'Rethinking EU Studies: The Contribution of Comparative Regionalism', Journal of European Integration 32(6), $541-62$. 
A. Warleigh-Lack, N. Robinson and B. Rosamond (eds) (2011) New Regionalism and the European Union: Dialogues, Comparisons and New Research Directions (London: Routledge), 36-56.

J-U. Wunderlich (2004) 'Towards a More Comprehensive Conceptualisation of Regions: The New Regionalism Revisited'. Paper presented at the 5th Pan-European SGIR Conference, The Hague, 9-11 September. 
Table 6.1 The 'regionness' scale

Type of region Description

Regional space

Regional complex

Regional society

Regional community

Region-state

Source: adapted from Hettne and Söderbaum (2000).
A geographically contiguous area, but one capable of transcending national borders.

A regional space in which human contacts and trade patterns have begun to be shaped on a cross-regional basis.

A regional complex in which cross-border regional transactions have intensified, become more dimensional and made subject to new regional rules; non-state actors gain meaningful roles in regional governance, and regional institutions may be established.

A regional society in which the region itself has become an actor, with its own collective identity underpinned by civil society mobilization at regional level, with national identities becoming less important and a sense of shared culture and/or polity deepening.

A new, heterogeneous state forms from the regional community, characterized by internal diversity, pluralism, and a multi-level distribution of power. 
Table 6.2 Strategies for comparative regional integration studies

\begin{tabular}{|c|c|c|}
\hline Strategy & Core issues & Example \\
\hline Unpacking regions & How do the member states & Restructuring of economic \\
\hline according to their & understand their statehood, and & space in Europe. Maintenance \\
\hline 'statehood' & how does this impact upon the & of sovereignty as key \\
\hline dimension & region? & organizing principle in Asia \\
\hline Relating & What limits and possibilities are & 'Asian values' and the \\
\hline integration & imposed by geography? How are & ASEAN Way. Colonial \\
\hline geographical and & historical processes and events & experiences and state-building \\
\hline \multirow[t]{3}{*}{ historical issues } & constructed and understood with & in Asia. Definitions \\
\hline & regard to the region? & 'Europe' \\
\hline & & enlargement. \\
\hline Combining & Issue-specific establishment of & Comparing EU and ASEAN \\
\hline nomothetic and & the comparability and & actorness, but comparing EU \\
\hline idiographic work & comparators of a region & and US as legal orders \\
\hline Bring in the intra- & Understanding & Comparing \\
\hline and inter-regional & constellations, inter-regionalism & governance complexes and \\
\hline \multirow[t]{2}{*}{ dimensions } & and regionalism-globalization & inter-regional relations (e.g. \\
\hline & relationship & ASEM and EU-MERCOSUR) \\
\hline
\end{tabular}

Source: adapted from Warleigh-Lack and Van Langenhove 2010.

\footnotetext{
${ }^{1}$ We are grateful to Edward Best for pointing out that a given region may conform to different typologies at once, given the fluidity of region-building.
} 
${ }^{2}$ On the differences between 'old' and 'new' regionalism, see Hettne 2002.

${ }^{3}$ This section draws on Warleigh-Lack and Van Langenhove 2010.

${ }^{4}$ Dorussen, Kirchner and Sperling (2010) provide material for intriguing hypotheses

here. Their work on national security cultures demonstrates that both the view of national sovereignty that a state elite holds (Westphalian or post-Westphalian?) and the national security culture of a state will shape that state's view of multilateralism and international cooperation more broadly. 


\section{University Library}

\section{- M M N E R VA A gateway to Melbourne's research publications}

Minerva Access is the Institutional Repository of The University of Melbourne

Author/s:

Murray, P;Warleigh-Lack, A

Title:

Europe-Asia Studies: The Contribution of Comparative Regional Integration

Date:

2013

Citation:

Murray, P. \& Warleigh-Lack, A. (2013). Europe-Asia Studies: The Contribution of

Comparative Regional Integration. Kirchner, E (Ed.). Christiansen, $T$ (Ed.). Jorgensen, K (Ed.). Murray, P (Ed.). The Palgrave Handbook of EU-Asia Relations, (1), pp.108-123.

Palgrave Macmillan.

Persistent Link:

http://hdl.handle.net/11343/247841 